\title{
El teatro de la imagen
}

\author{
The theater of Image
}

\author{
Juan Gustavo Cobo Borda \\ coboborda@gmail.com \\ Poeta y escritor
}

\section{Resumen \\ El escritor y poeta Juan Gustavo Cobo Borda explora la obra de Andrés Romero Baltodano y, al adentrarse en su trayectoria como fotógrafo, revela al teatro como una de sus influencias.}

Palabras clave: Imagen, fotografía, teatro, Alejandra Pizarnik

\begin{abstract}
Poet and writer Juan Gustavo Cobo Borda, explores the work of Andrés Romero Baltodano and, by going deep into his trajectory as a photographer, reveals theatre as one of his main influences.
\end{abstract}

Keywords: Image, photography, theatre, Alejandra Pizarnik

\begin{tabular}{|c|c|c|}
\hline & $\begin{array}{r}7 \\
13 \mathrm{~d} \\
6 \text { de ser }\end{array}$ & $\begin{array}{l}\text { RA CITAR ESTE ARTículo / TO CITE THIS ARTICLE } \\
\text { obo Borda, J. El teatro de la imagen. Poliantec } \\
151,217-222 \text {. }\end{array}$ \\
\hline
\end{tabular}

POLIANTEA | PP. 217-222 | VOLUMEN VIII | NÚMERO 15| JULIO-DICIEMBRE 2012 
- El teatro de la imagen - Juan Gustavo Cobo Borda 


\title{
El teatro de la imagen
}

\begin{abstract}
Juan Gustavo Cobo Borda
Poeta y ensayista bogotano. Fue director durante una década (1973-1984) de la revista Eco, de la librería Buchholz, y Gaceta, del Instituto Colombiano de Cultura. Ha ocupado cargos diplomáticos en Buenos Aires y Madrid y fue embajador en Grecia. Miembro número de la Academia Colombiana de la Lengua desde 1993, y correspondiente, de la Academia Española. Ha sido jurado tres veces del Premio Juan Rulfo, (Guadalajara, México); del Rómulo Gallegos, (Caracas); del Reina Sofía de poesía iberoamericana (Madrid) y del Neustad, Universidad de Oklahoma, Estados Unidos. Ha colaborado con otras publicaciones, como Plural, de México, ABC, de España, y El Nacional de Venezuela.
\end{abstract}

Entre sus poemarios figuran Consejos para sobrevivir (1974); Todos los poetas son santos (1987); Dibujos hechos al azar de lugares que cruzaron mis ojos (1991) y La musa inclemente (2001), entre otros. Algunas de sus publicaciones son Lengua Erótica: antología poética para hacer el amor (Villegas Editores, 2004), Lector impenitente, El olvidado arte de leer, Enclave de palabras número tres Acosado animal (Politécnico GrancoIombiano, 2010), Vargas Llosa: La pasión de narrar (Alfaguara, 2010), sus más recientes publicaciones.

Dos influjos marcaron la infancia de Andrés Romero Baltodano. Su padre, el fotógrafo Ricardo Romero Castany, quien era concesionario de Kodak para Centroamérica y su madre nicaragüense, Beatriz Baltodano, quien al regresar a Colombia desarrollaría con entusiasmo sus intereses artísticos. Se inscribiría en la Escuela de Arte Dramático y participaría en encuentros sorprendentes como la visita de Marcel Marceau a Bogotá y un seminario, quizás mudo, que dictó en el país.

Pero también su madre incursionó en un teatro más renovador como el que desarrolló Dina Moscovici montando las primeras obras de lo que se llamó teatro del absurdo y que bien podían ir de Ionesco a Arrabal sin olvidar a Samuel Beckett. Un teatro experimental de pequeñas salas, un tanto precarias, y de seminarios, un tanto aleatorios en la Universidad Nacional donde los primeros cursos de Dina dialogaban con los de su marido Francisco Posada, uno de los primeros estudiosos de la obra de Bertolt Brecht desde la perspectiva filosófica de un marxismo preocupado por el realismo y la estética (Posada, 1969). 
Todo lo viviría de niño Andrés Romero, nacido en 1961, y quizás por ello dedicaría diez años de su vida como fotógrafo autodidacta a registrar los escenarios del teatro, las artes escénicas ${ }^{1}$, donde no sólo se presentan y representan los dramas humanos sino también en las escenografías se cruzan luces y artilugios mecánicos, sombras, maquillajes, fuego y humo, e inverosímiles proezas físicas que anudan gimnasia con ballet y en general la tensión dinámica de un cuerpo expresivo al volver comunicación un gesto una torsión, un escorzo.

Esto lo llevaría, de modo casi inevitable, a estudiar dirección de Cine y Televisión en la Universidad Nacional de Colombia donde enlazaría con otra de sus pasiones: la literatura. Su tesis de grado, de 24 minutos, sería una película sobre Alejandra Pizarnik ${ }^{2}$, la poeta argentina suicida y cultivadora también

I Por su trabajo, Andrés aparece reseñado en el libro "Historia de la fotografía en Colombia 1953-2000", en el apartado de Artes escénicas.

2 Sobre Alejandra Pizarnik el primer trabajo que apareció en Colombia fue J.G. Cobo Borda: "La pequeña sonámbula", en la revista ECO, No. 152, noviembre de 1972,. Ahora se halla recogido en J.G. Cobo Borda: Lector impenitente, México, Fondo de Cultura económica, 2004 (p.356-368). de la pintura, que con el título de "Romanza para una sonámbula inconclusa" (1992) la muestra, sin texto un palabras, presa en la jaula del lenguaje, su condición de lesbiana, de sus ancestros judíos, apenas con la sugerencia poética del silencio. Ello se prolongaría en una indagación también fílmica sobre el mentor y protector de Pizarnik: Julio Cortázar, Julio está saltando al cielo (1991). Territorio, como recalcaría Cortázar, de encuentros lunares a deshora (Pizarnik, 2008).

Ese ir y venir entre imagen visual, palabra escrita y reportería gráfica, al captar cómo se vive en la calle un mundo ya superpuesta de figuras que expuestos en muros y carteleras también nos contemplan a nosotros como espectadores permanentes de esa sala de exposiciones que es la ciudad, lo obligaran a reflexionar sobre su oficio, a establecer una tradición con la cual vincularse. Tal como sucedería con el narrador, en fotos, también nacido en Aracataca y residente por muchos años en México: Leo Matiz. El fotógrafo de Diego Rivera y Frida Kahlo. El galerista pionero de la moderna pintura colombiana. Un fotógrafo que en alguna forma señala uno de los lugares que Andrés 
Romero ha querido hacer suyo, en la ampliación de las fronteras mentales colombianas. Uno sería México. El otro Cuba.

“Ha pasado la cámara a sustituir el ojo de Dios?, ¿el declive de la religión coincide con la aparición de la fotografía? ¿acaso la cultura del capitalismo ha asimilado a Dios a la fotografía?", tal como se pregunta John Berger (1998, pp.67-84) en su texto "Usos de la fotografía", de su libro Mirar (Berger, 1998).

Por ello es necesario captar todo, los rostros y los deportista, y a ambos, en los enfoques y en los títulos, enriquecerlos con las sugerencias que brinda la pintura, llámese Hopper o Balthus. ${ }^{3}$ Todo lo cual convergerá en su serie para televisión El libro de la almohada (2003), serie de veintiún capítulos donde se entrevistará a narradores como Jorge Volpi, Rodrigo Fresán o Luis Rafael Sánchez y a filósofos como Lipovetsky. También a su proyecto cultural La Moviola ${ }^{4}$, con cinco años

3 En su obra fotográfica actual, los títulos aducen a series que son homenajes a pintores como Balthus o Hopper o Richter. Para conocer la obra de Andrés: http:// www.flickr.com/photos/andres_romero_ baltodano/

4 Disponible en: hitp://lamoviolacineclub. blogspot.com/ y ochenta ediciones, que se constituye así en un cine club, de una revista alternativa multicultural y en continuar en sus creaciones de video arte, como aquella que llevó invitado a la VIII Bienal de la Habana, para hablarnos de la violencia en Colombia desde las funerarias cercanas al Hospital de la Hortúa, con el título Desvanecerse entre árboles mojados (2003), de su manual de guion que publicaría el Politécnico Grancolombiano con el título Palabras Fantasmas, pantallas voraces. Apuntes para un guión creativo.

Desde fotos abstractas hasta marchas de todo tipo por las calles, el trabajo de fotoperiodismo de Andrés Romero Baltodano buscan poner a dialogar lo personal y lo público en el teatro que nunca cierra sus puertas ni bajas sus telones. El teatro de la mirada y el teatro de la memoria que algo preserva de la fragilidad impaciente de nuestras horas.

\section{Referencias bibliográficas}

Berger, Jhon (1998). Mirar. Buenos Aires. Ediciones La Flor. 
Cobo Borda, Juan Gustavo (2004). Aires, 2008, p.245-251. La nota Lector impenitente, México: Fondo está fechada en 1967. de Cultura económica.

Posada, Francisco (1969). Lukacs, Pizarnik, Alejandra, "nota sobre Brecht y la situación actual del reaun cuento de Julio Cortázar: El lismo socialista. Buenos Aires: otro cielo" en Alejandra Pizarnik: Editorial Galerna.

Presa completa. Lumen, Buenos 